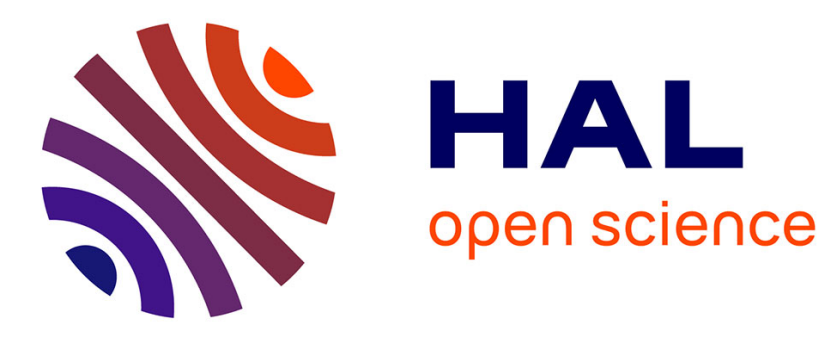

\title{
Odour and Life Cycle Assessment (LCA) in Waste Management: A Local Assessment Proposal
}

Mathilde Marchand, Lynda Aissani, Pascal Mallard, Fabrice Béline, Jean-Pierre Réveret

\section{To cite this version:}

Mathilde Marchand, Lynda Aissani, Pascal Mallard, Fabrice Béline, Jean-Pierre Réveret. Odour and Life Cycle Assessment (LCA) in Waste Management: A Local Assessment Proposal. Waste and Biomass Valorization, 2013, 4 (3), pp.607-617. 10.1007/s12649-012-9173-z . hal-00866004

\section{HAL Id: hal-00866004 https://hal.science/hal-00866004}

Submitted on 9 Dec 2014

HAL is a multi-disciplinary open access archive for the deposit and dissemination of scientific research documents, whether they are published or not. The documents may come from teaching and research institutions in France or abroad, or from public or private research centers.
L'archive ouverte pluridisciplinaire HAL, est destinée au dépôt et à la diffusion de documents scientifiques de niveau recherche, publiés ou non, émanant des établissements d'enseignement et de recherche français ou étrangers, des laboratoires publics ou privés. 


\title{
Odour and Life Cycle Assessment (LCA) in waste management: a local assessment proposal
}

\author{
Mathilde Marchand ${ }^{1,2}$, Lynda Aissani ${ }^{1,2}$, Pascal Mallard ${ }^{3}$, Fabrice Béline ${ }^{1,2}$ and Jean-Pierre \\ Réveret $^{4}$ \\ ${ }^{1}$ - Irstea, UR GERE, F-35044 RENNES Cedex, France \\ 2 - Université Européenne de Bretagne, France \\ 3 - DREAL Bretagne L'Armorique, F-35065 RENNES Cedex, France \\ ${ }^{4}$ - UQAM, MONTREAL, Québec H2X 1L7, Canada \\ Contact: PhD Student Mathilde MARCHAND, Irstea, UR GERE, 17 Avenue de Cucillé - CS \\ 64427, F-35044 RENNES Cedex, France - (+33) 2.23.48.21.06. - lynda.aissani@irstea.fr
}

\section{EXECUTIVE SUMMARY}

Environmental assessment of Municipal Solid Waste (MSW) management is essential. Life Cycle Assessment (LCA) is a powerful and widely used method, which implements causal chains (impact pathways) between the studied processes and their environmental impacts. However, in waste management, the method presents some weaknesses. For example, there is no impact category related to odour, whose assessment is nevertheless essential, especially when the organic fraction of waste is concerned. Odour interferes with human welfare and comfort. Sometimes, it can become a nuisance and be described as a "socio-environmental" impact.

To integrate the impact of odour in waste management plans, it is necessary to build an odourimpact pathway. The aim of this paper is to present a first attempt to build such an impact pathway up to the so-called midpoint step (i.e. the level of discomfort to human beings).

The methodology we developed is based on the cause/effect chain according to the descriptors of the Site Dependent approach. Unlike classical LCA, the classification step is more important and characterization is aimed at computing the characterization factor. The change in this classification step allows for working on the occurrence of odour impacts. To determine impact occurrence, it is necessary to integrate local conditions into odour assessment. This was done using (i) the USEtox model in which local conditions to assess odour impacts are integrated and (ii) the framework of a new methodology that takes into account background concentrations).

The methodology was implemented in a case study, i.e. by computing atmospheric emission of ethyl benzene during composting $\left(2.93 .10^{-2} \mathrm{~kg} \cdot \mathrm{d}^{-1}\right)$. The characterization factor for ethyl benzene was equal to $3.02 .10^{-3} \mathrm{~kg}$ eq. Benzene $\mathrm{per} / \mathrm{kg}$ emitted ethyl benzene. The daily emission of ethyl benzene generated an odour impact equal to $6 \cdot 6 \cdot 10^{-5} \mathrm{~kg}$ eq. benzene.

With that first odour mid-point impact, we paved the way for the construction of a whole odour pathway (going up to end-point impacts or damages). However, several limits were identified such as data availability, the model under use and the use of average daily data which is less relevant than emission peaks. We should also recall that our methodology is not intended for predicting nuisance likely to disturb populations living nearby the facility. Its first objective is to provide an indicator that fits with LCA methodology in order to help local decision-makers to differentiate waste management scenarios based on exhaustive LCA.

Keywords: Odour, Waste Management, Life Cycle Assessment (LCA), USEtox, Spatial differentiation 


\section{Introduction}

In Europe, the amount of waste produced in some countries is related to the degree of urbanization, types and patterns of consumption, as well as to households' income level and lifestyle. In 2009, Western Europe inhabitants (EU 27) produced an average $513 \mathrm{~kg}$ of Municipal Solid Waste (MSW) [1], while French inhabitants produced $535 \mathrm{~kg}$. The French production of MSW appears to have stabilized to around 42 million tons per year for several years.

In 2009, 7.8 million tons were recycled, 5.5 million tons were treated in organic plants, 11 million tons were turned into energy and 10 million tons were eliminated in landfills (Figure 1).

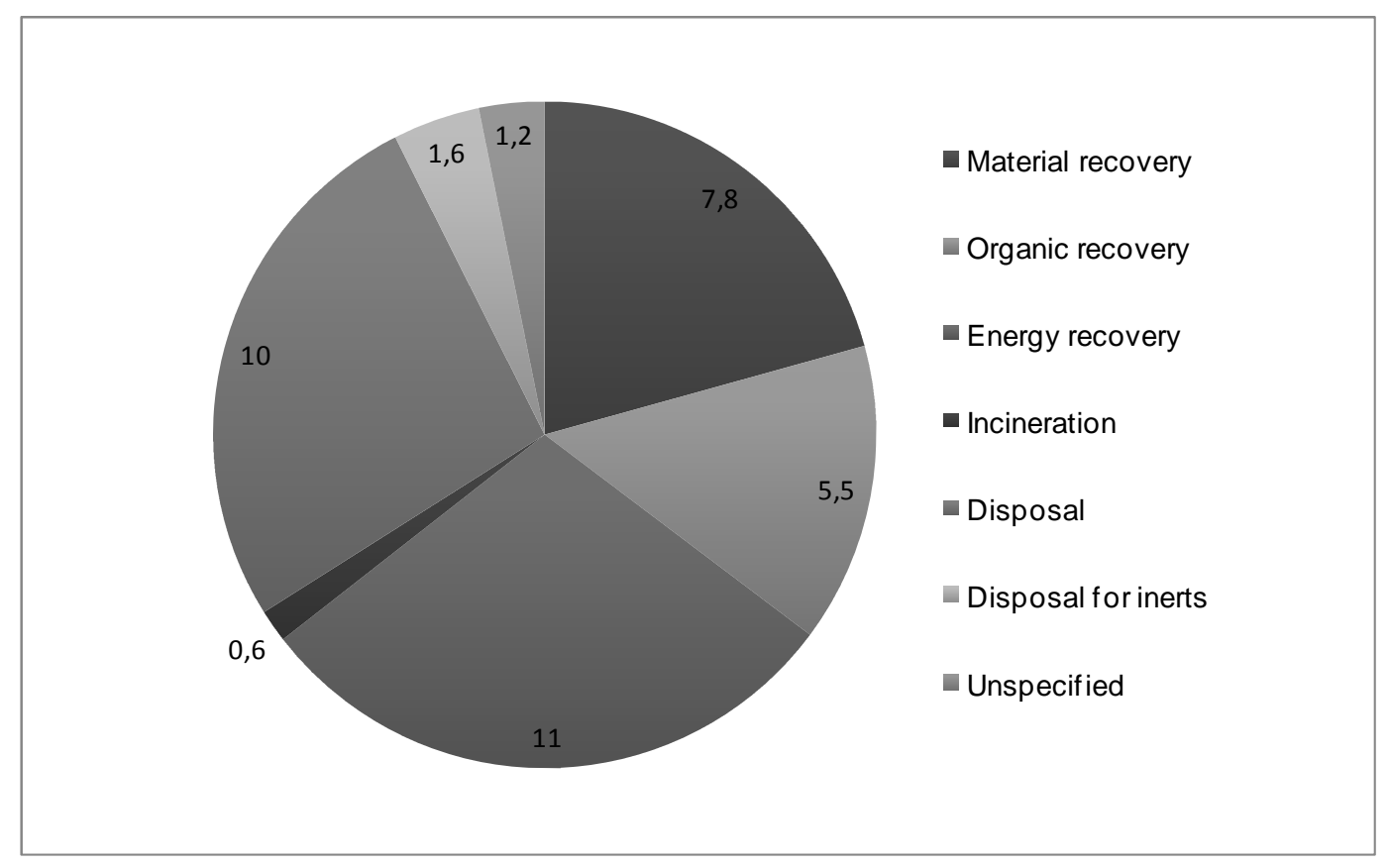

Figure 1: French household waste in 2009 (million tons)

Along with time and production changes, waste management in Europe and France had become a major priority [2-3]. However, MSW are managed at a local scale such as counties in France. Pressure on local decision-makers requires them to integrate local issues in their decisions. Local management is based on local environmental issues which are determined by local conditions.

The importance of local issues is steadily increasing for regulatory but also for ideological reasons. To get approval from the population, local decision-makers have to integrate local issues into decision-making.

To improve waste management and in particular to reduce its impacts, consulting offices that help local decision-makers use different environmental assessment tools for decision support such as the Ecological Footprint, the Carbon Footprint or Life Cycle Assessment (LCA). LCA appears to be more often used with regard to its multi-criteria character. However, despite its advantages, it presents some methodological and application limitations. Many of these limitations are intrinsic to the methodology and some are related to its application to the field of waste management.

LCA makes it possible to assess the potential environmental impacts of a system or product by identifying and quantifying the associated inputs and outputs. LCA is defined by ISO 14040 [4] as "a compilation of inputs, outputs and potential environmental impacts of a product system throughout its life cycle". The input and output flows of a system, identified in the inventory step (the second step of the LCA methodology) are linked to their potential environmental impacts, 
through causal chains called pathways. Their application field is quite large, because several impact categories can be assessed in the same study.

According to the standard ISO 14040 [4] and the SETAC, LCA methodology is divided into four steps:

- Goal and scope definition. The reasons for carrying out the LCA study are explained [45] and the purpose, the scope, the nature and the function of the system, the functional unit and the boundaries are determined;

- Inventory analysis: mass and energy flows throughout the system are quantified from mass and energy balances and turned into consumption and emission flows, called inventory data; inventory data must be related to the functional unit which is at the basis of inventory quantification.

- Impact assessment. The relationship between inventory data and potential environmental impact are established in two steps: classification, which assigns emission/consumption values to the different impact categories, and characterization, which quantifies potential environmental impacts [4]. The term "potential" is used because calculated impacts in LCA are not "real" impacts but possible ones, due to missing knowledge about the environmental fate of compounds, the mechanisms of impact occurrence but also synergy or antagonism phenomena between compounds [6-7].

- Interpretation of results, based on the results from the previous steps. It is possible to conclude and issue recommendations (consistent with the objectives) to identify actions aimed at reducing the impact of human activities on the environmental system.

The use of LCA in MSW management, called "waste LCA" here, is a voluntary initiative aimed at informing decision-makers from a global environmental perspective. Waste LCA can be performed for different reasons. At a regional scale, waste LCA allows us to compare different waste management scenarios. At a national scale, waste LCA allows us to assess waste policies. In this paper, we deal with waste LCA at a regional scale.

The methodological specificity of waste LCA is its scope definition. In this study, the term "life cycle" refers to when the product becomes a waste that the owner wishes to dispose of (Figure 2).

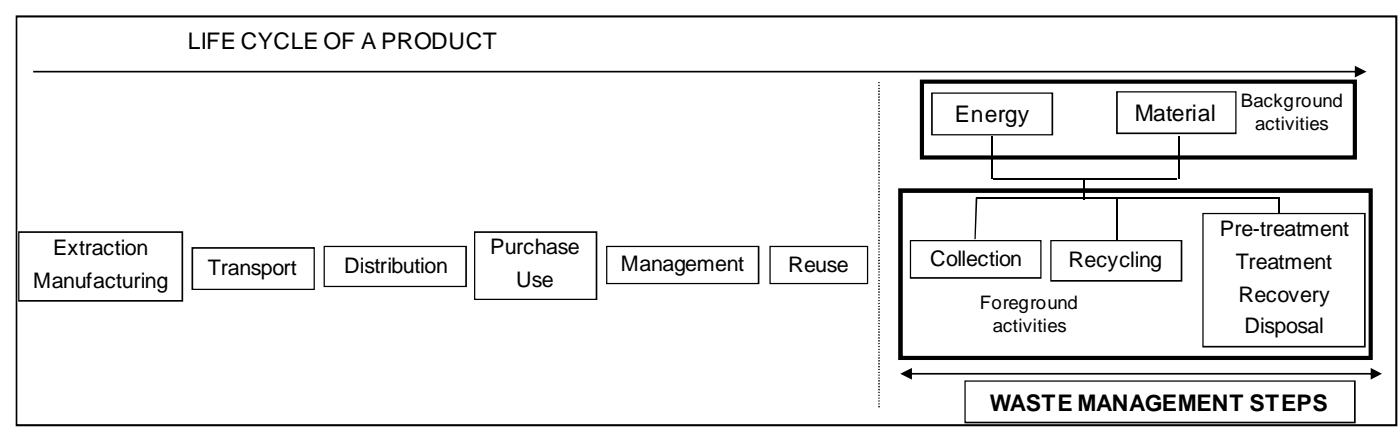

Figure 2: Scope of LCA applied to MSW management

This means that waste LCA does not include emission and consumption associated to previous life cycle steps, i.e. before a product becomes a waste. Different steps of waste management are integrated: collection, sorting, transfer, recycling, recovery (with pre-treatment and treatment), i.e. energy and material collection, recovery and disposal. Waste production prevention is usually not taken into account because it especially concerns consumption patterns, although some authors consider that it is part of waste management and should therefore be included in waste LCA [8].

The collection and treatment steps are called "foreground activities" (Figure 2), as impacts related to these steps are directly related to waste management, and the geographical scale of these activities is local. Decision-makers can monitor and control these activities, as opposed to "background activities" which are often located at another geographic scale and are indirectly 
related to waste management (for example fuel production). Our research is focused on foreground activities because they are mainly concentrated at the local scale.

The methodological bottleneck of waste LCA is that LCA does not relevantly assess local impacts and that some relevant impact categories are lacking. A literature review of waste LCA between 1998 and 2011 allowed us to identify MSW issues which were not sufficiently dealt with, i.e. human toxicity and odour. The aim of this paper is to describe the development of a new impact category related to odour.

First, we emphasize the need for this impact category, then we present the methodology for designing the impact pathway and finally we apply it. The fact that spatial differentiation is limited or absent (spatial and temporal parameters of emission and target populations are not integrated) poses a problem in the local impact assessment context of odours. Integration of local impact assessment into LCA will have to be improved by taking into account spatial and temporal conditions.

\section{The odour issue in waste management}

In the field of waste management, odour causes dissatisfaction and many complaints from local populations. In France, odour represents the second cause for complaints after noise [9].

The word "odour" is specifically defined as a molecule that can be perceived by a human being or an animal and which generates various impressions (pleasant, unpleasant, or indifferent).

In waste management, odours are caused by the biodegradation of organic matter during either aerobic (composting) or anaerobic (anaerobic digestion) processes. Odorous emissions vary according to the type of organic waste and the technical parameters of the process.

In waste management decision-making, odour nuisance is often related to composting facilities projects. Composting plants are considered as a source of unpleasant odour emissions which can cause olfactory nuisance to the people living nearby. The growing demand from local populations in terms of quality of life and well-being increases the number of olfactory assessment studies in the field of waste management. To quantify that nuisance, engineering consulting firms use the normative framework which defines the baseline of olfactometry (odour analysis): nose juries are formed, and laboratory materials and procedures are defined. However olfactometry is an $a$ posteriori approach and does not meet the needs of prospective approaches that need an a priori assessment (for example during waste management planning). In decision-making, odours must therefore be assessed in the same way as other conventional environmental impacts (like global warming for example) in a priori assessment procedures. Moreover, odours can have an impact on health: repetitive unpleasant odours are not only a discomfort but can also have an adverse effect on population health by causing stress, fatigue and even depression [10]. To take this parameter into account in environmental assessments, and especially in LCA, it is necessary to build a new impact category as well as a new impact pathway. The latter corresponds to the causal chain from gaseous emission to its final effect on environment (Figure 3). 


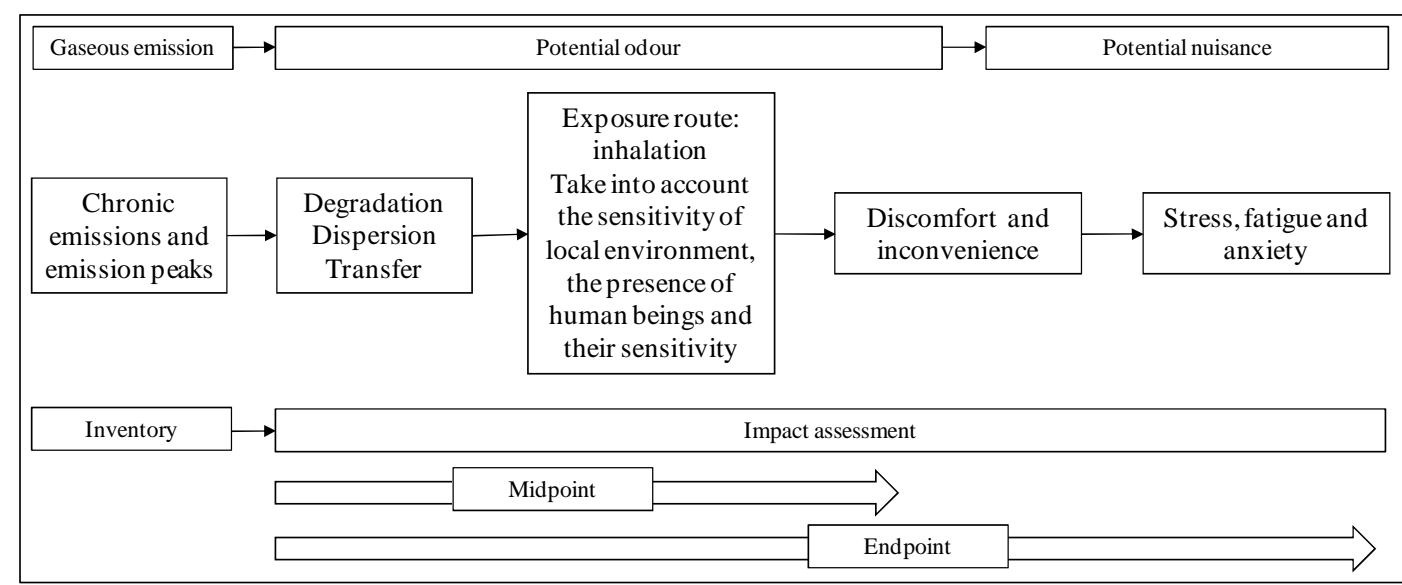

Figure 3: Complete odour impact pathway

This study aims at building up that pathway, with the following limits: we only consider chronic emissions and emission peaks in normal functioning (degraded functioning is not taken into account) and we stop at the discomfort and inconvenience step that we call "effect". We do not consider the route from effect to odour-caused damage, i.e. stress, fatigue and anxiety.

\section{The need for a local approach in odour pathway development}

The pathway from emission to effect highly depends on local conditions which influence the fate of compounds within the environment, exposure parameters and effects on targets. It is easy to understand that if these local conditions are not taken into account in assessments, the robustness of the study can be questioned.

To take into account spatial and temporal conditions, it is necessary to focus on the second and third steps of LCA, i.e. inventory and impact assessment steps. In classical LCA, it is assumed that a standard environment is impacted. This is called the Site Generic approach. According to this approach, the characteristics of impacted environments (where emission takes place after physical, chemical and biological phenomena) do not influence the occurrence or the intensity of impacts because they do not taken into account in assessment. This approach is relevant for global impacts (global warming, depletion of the ozone layer or depletion of fossil resources), but not when local impacts are dealt with (e.g. eutrophication, ecotoxicity, toxicity...). For toxicity, it is necessary to take into account emission characteristics, environmental distribution, background concentrations (i.e. taking into account the compound which is already present in the medium) and target sensitivity [6]. For these reasons, spatial differentiation is absolutely needed. It can be carried out using the Site Dependent approach.

Potting and Hauschild established a preliminary basis for the Site Dependent approach [7]. This approach is built according to the theoretical cause/effect chain leading to an environmental impact. The chain describes the mechanism whereby an impact results from the emission of a compound in the environment (Figure 4). The link between the amount of emitted compounds and the intensity of their environmental impacts is made of the successive steps of the cause and effect chain.

Unlike what is classically done in LCA, we do not use this cause/effect chain for impact quantification but to determine impact occurrence. 


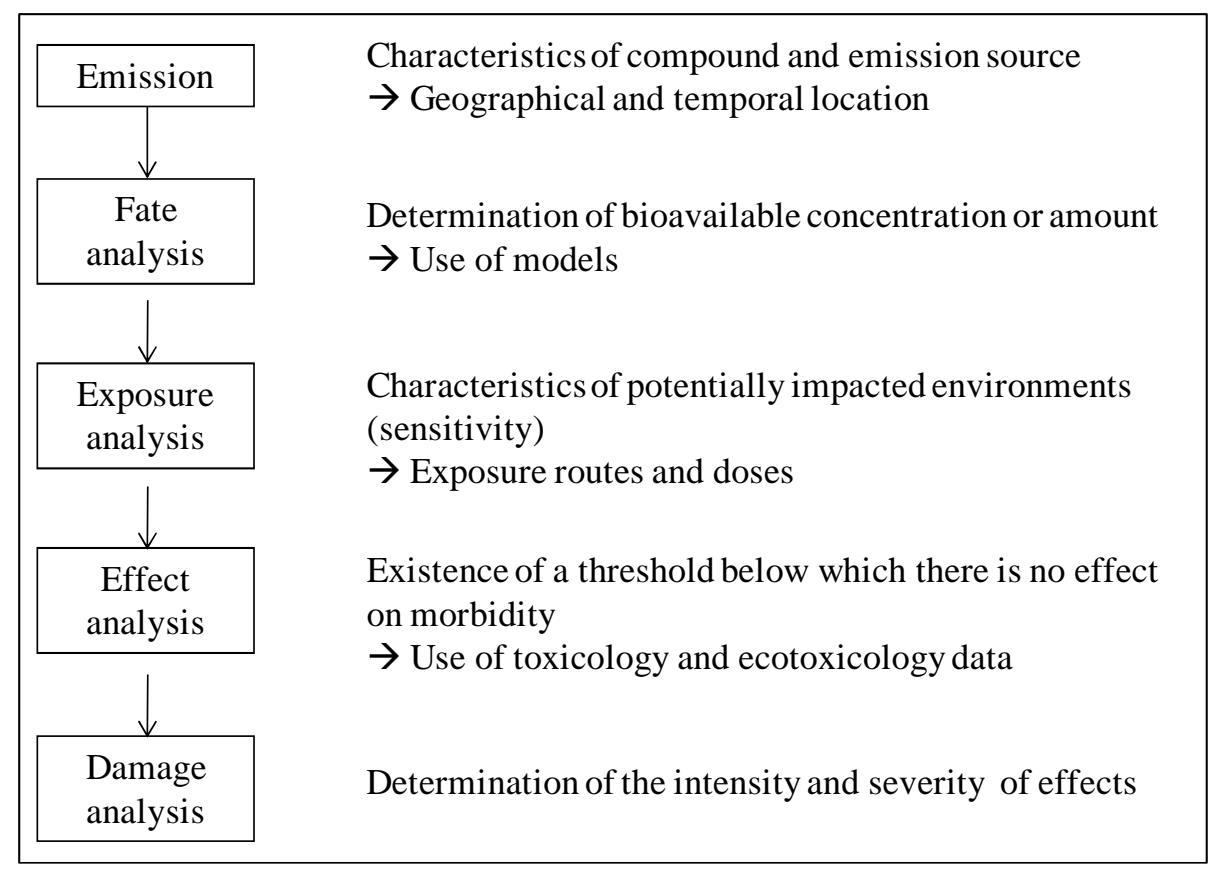

Figure 4: Cause/effect chain of environmental impacts

Aissani (2008) highlighted the pervasiveness and the importance of spatial and temporal parameters throughout the cause/effect chain of a local impact [11]. They determine the appearance and intensity of the environmental impacts.

According to that chain, the Site Dependent approach is made up of five items with the following descriptors:

- Characterization of emission and emission source: quantity, time/frequency, emission compartment (air, water, soil), location and source type;

- Fate analysis: compound distribution between environmental compartments, dilution, immobilization, removal and degradation;

- Exposure analysis: characteristics of the impacted environment (sensitivity), increase of environmental and background concentrations;

- Effect analysis: no-effect concentration and critical concentration;

- Damage analysis: type and magnitude of the impact.

In this study, the chain is built up to the effect analysis. Local parameters are integrated using the USEtox model.

\section{The new methodology framework}

This new methodology aims to develop the first steps (i.e. up to the effect analysis) of a pathway for odour as a new impact category (Figure 3). The main challenge of this new methodology is to determine the potential effect of an odorous emission on a human population.

According to Figure 3, the odour impact pathway is built from the following items:

- Emission: we consider chronic emissions and emission peaks;

- $\quad$ Fate analysis: we take into account degradation, dispersion and transfer phenomena;

- Exposure analysis : the only exposure route considered is inhalation;

- Effect analysis: we determine the effects of odorous compound emission on human beings; 
- Damage analysis: we define the effect on human health in the long term.

The methodology should follow LCA methodology for any impact assessment, i.e. a classification step based on the cause/effect chain to determine impact occurrence, and a characterization step based on the calculation of a characterization factor if impact occurrence is confirmed. The purpose is to calculate a potential disturbance impact defined for different types of odours. The link between potential odour and potential damage (nuisance), including impacts on human health, is not developed here.

\subsection{Classification}

This new methodology framework follows the cause/effect chain according to the descriptors of the Site Dependent approach. In LCA, a similar cause/effect chain has already been modelled using a mechanistic model called "USEtox".

\subsubsection{The USEtox model}

USEtox results from a scientific consensus based on comparison of existing models for toxicity assessment [12]. It is becoming a reference to assess toxicity in LCA. It is built according to the Site Dependent approach to calculate characterization factors for human toxicity and aquatic ecotoxicity in different environmental compartments (air, water and soil) [13]. Throughout the cause and effect chain, the model determines fate, exposure and effect analyses in order to obtain a set of characterization factors (Figure 5).

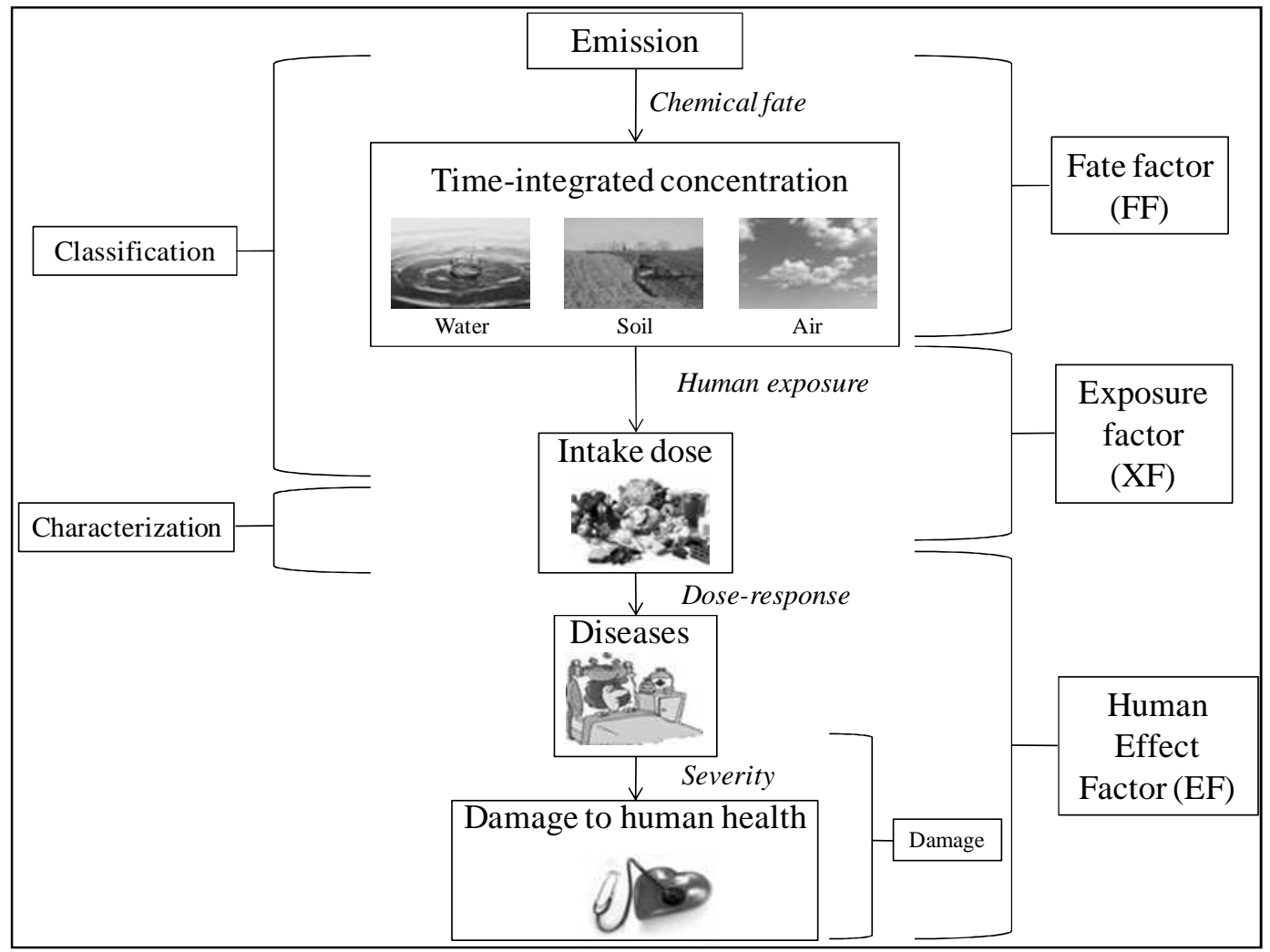

Figure 5: The USEtox framework

The characterization factor is calculated from the fate (FF), exposure (XF) and effect (EF) factors (Eq1). 
The USEtox model is a nested model that works across three environmental compartments, i.e. global, continental and urban boxes. The first two boxes are composed of several environmental compartments, i.e. air, fresh water, sea water, agricultural soils and natural soils, whereas the urban box is made up of the air compartment only. The global box represents the earth with global data. The continental box is a virtual continent, i.e. an average value of all continents on earth from average continental data. This is similar for the urban scale where average urban data are used. Each box is set with data according to its scale (Figure 6a). In our study, the scale of boxes is different from USEtox default version and they need to be modified.

\subsubsection{Emission characteristics}

As in classical LCA, the inventory step deals with identifying emission, here the odorous compounds emitted by composting facilities. The aim of this part is:

- To determine whether the compound can generate an odour impact;

- To get spatial information relevant for future fate analyses.

This methodology is only carried out for compounds previously identified and routinely produced by the composting process of municipal waste.

After the classification step, the main characteristics of the emitted compound, its emission and emission compartment have to be defined:

- Emission type (smokestack or diffuse emission);

- Emission frequency (occasional or chronic emission);

- Period of emission (long or short);

- Emission compartment (air, water or soil);

- Emitted quantity;

- Physical, chemical and biological characteristics of the compound;

- Physical, chemical and biological characteristics of the emission compartment.

\subsubsection{Fate analysis}

Fate analysis is necessary to take into account transfer, degradation and diffusion of compounds after their emission. It allows us to determine the compound concentrations people are exposed to. It is performed using the USEtox framework. However, for odour impact assessment, the use of the USEtox model for fate analysis is restricted to determining the environmental concentration of the compound after emission. It is necessary to adapt USEtox. Indeed, in odour assessment the urban and continental scales are macroscopic.

To adapt USEtox to an odour context, the size of the three boxes and their environmental compartment characteristics (such as temperature, wind speed, rain rate...) have been changed (Tab 1). This scale change has led to the modification of transfer between local fresh water and global fresh water. 
a)

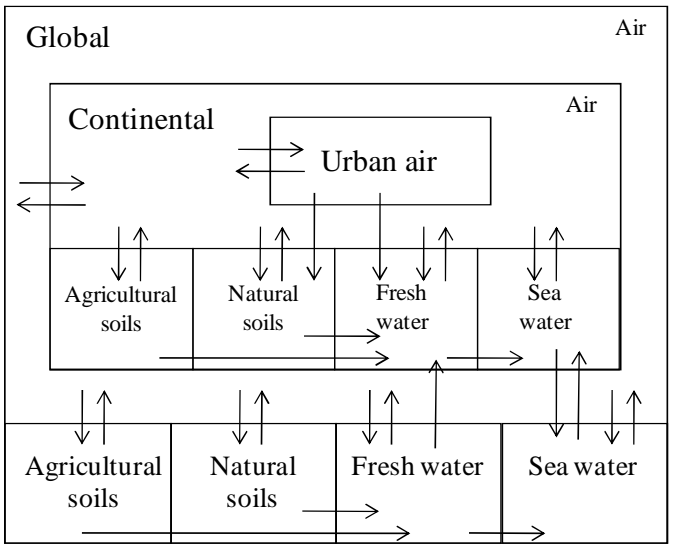

b)

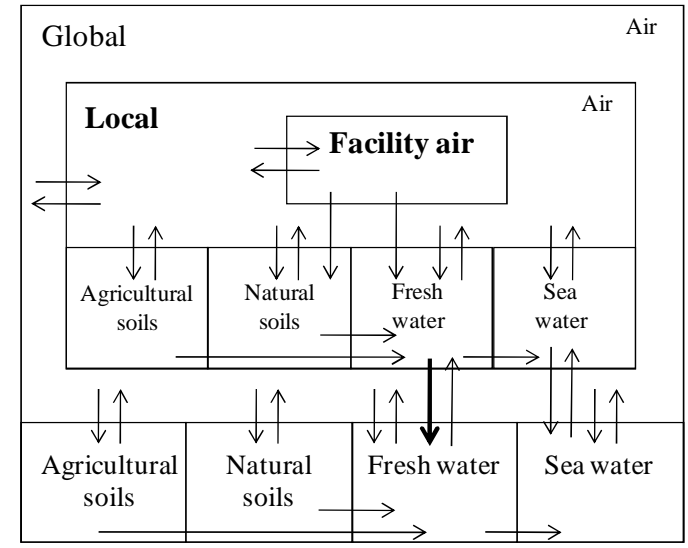

Figure 6a and b: USEtox box translation (from a) to b)) for local impact assessment and transfers between environmental boxes and compartments

A sensitivity analysis was performed to identify the relevant and sensitive parameters of the environmental compartments in the USEtox model. Among all the environmental parameters reported in USEtox (Tab 1), only three seemed relevant for odour assessment and were therefore submitted to a sensitivity analysis: temperature, wind speed and rain rate. For the other parameters (for example: depth of fresh water, river flow, and run-off fraction) default values present in USEtox are used. After changing box sizes and the choice of sensitive parameters, the fate analysis was performed and the environmental concentration of the compound was calculated consistently with the Site Dependent approach.

\subsubsection{Exposure analysis}

The exposure analysis aims to incorporate a spatial dimension to determine whether the geographic location of the emission and the presence of human beings sensitive to the emitted compound coincide. The exposure concentration is the sum of the concentration due to current emission (previously calculated with USEtox model) and of the background concentration of the compound, i.e. the amount of the compound currently present in the environment, independently of the considered emission [6]. Adding the background concentration allows us to take into account local conditions of impacted environments and to obtain the real exposure concentration.

\subsubsection{Effect analysis}

The effect analysis allows for determining the effect of a compound on human beings. To define that effect, we calculated an Effect Ratio (ER) from the exposure concentration and olfactory threshold of the studied compound (Eq2).

$\mathrm{ER}=\frac{[\mathrm{sub}]_{\text {expoi }}}{\text { Olfactory threshold sub }}$

The olfactory threshold is available in chemical databases. The effect ratio can be distributed into three intervals (Figure 8 ): $[0 ; \alpha],[\alpha ; \beta]$ and $[\beta ;+\infty[$. The $\alpha$ parameter is a "safety factor". This safety factor is set to $1.10^{-3}$ for our preliminary research work. The $\beta$ parameter is 1 . When the effect ratio is in the first interval, we consider there is no olfactory impact risk. When the effect ratio is in second or third intervals, we consider there is an olfactory impact risk. However, in the second interval, we admit the existence of a "fuzzy zone" related to the cocktail effect which is not taken into account. When the effect ratio is in the third interval, the characterization factor and the impact are calculated, as shown in the next section. 


\subsection{Computation of the characterization factor and quantification of the odour impact}

The characterization factor is not calculated the same way as in USEtox. Besides the determination of fate, exposure and effect factors is also different.

The characterization factor involves not only the studied compound but also a reference compound. The latter is defined from the compost wheel [14]. For each odour type, we identify one reference compound (Figure 7). For example, in the odour type "solvent/hydrocarbon", we choose the benzene compound as a reference compound. In the "sweet" type we choose the butanone compound as reference. We propose that the characterization factor be the ratio of the olfactory threshold of a studied compound and the one of its reference compound.

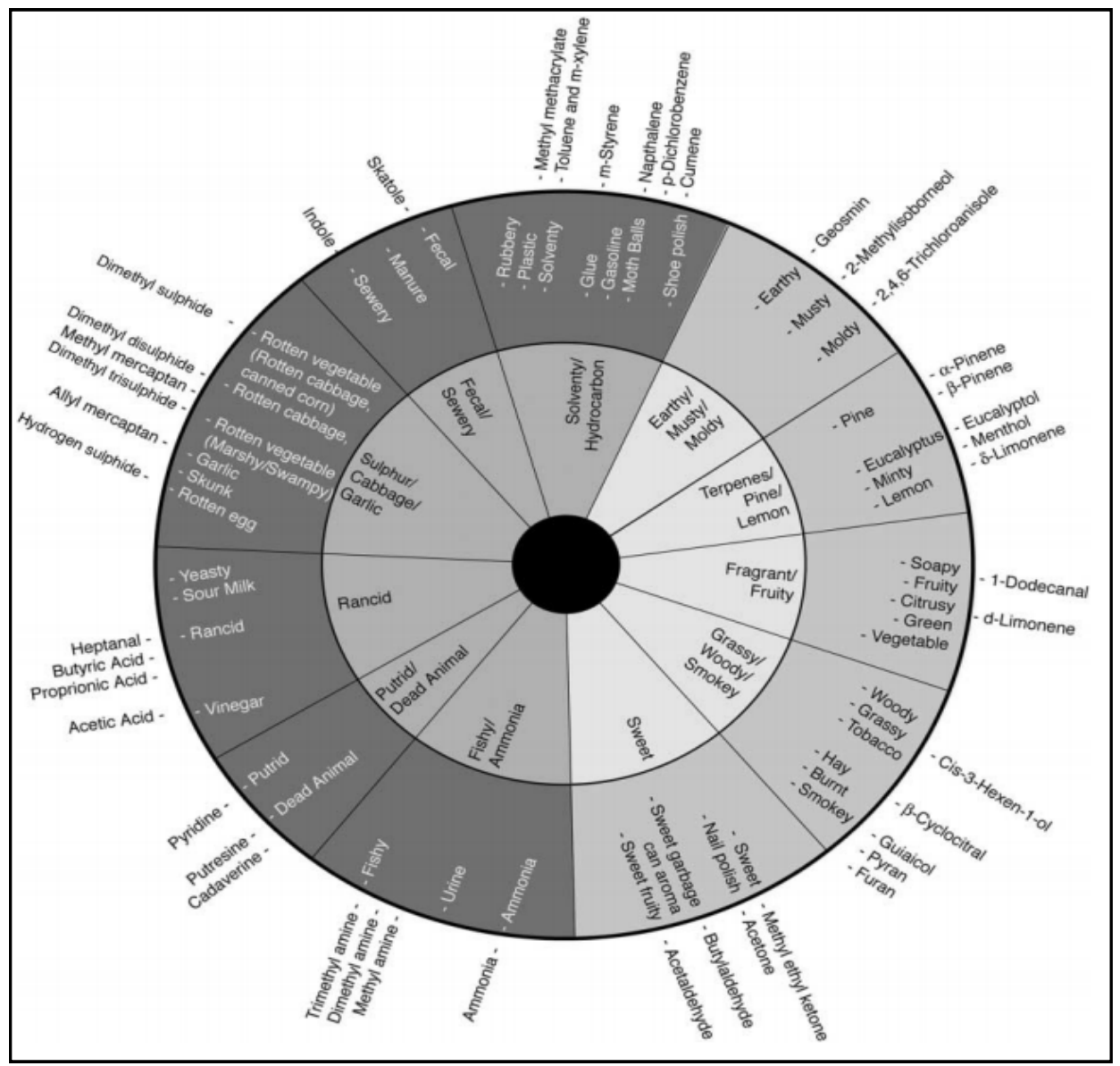

Figure 7: Compost odour wheel

The odour impact is then calculated by multiplying this characterization factor by the mass of the emitted compound (data obtained in the inventory step).

\subsection{A new framework scene}

The different items previously developed lead to a new methodology which consists in two steps: a complex classification procedure to check that an impact does exist, and impact characterization (Figure 8). 


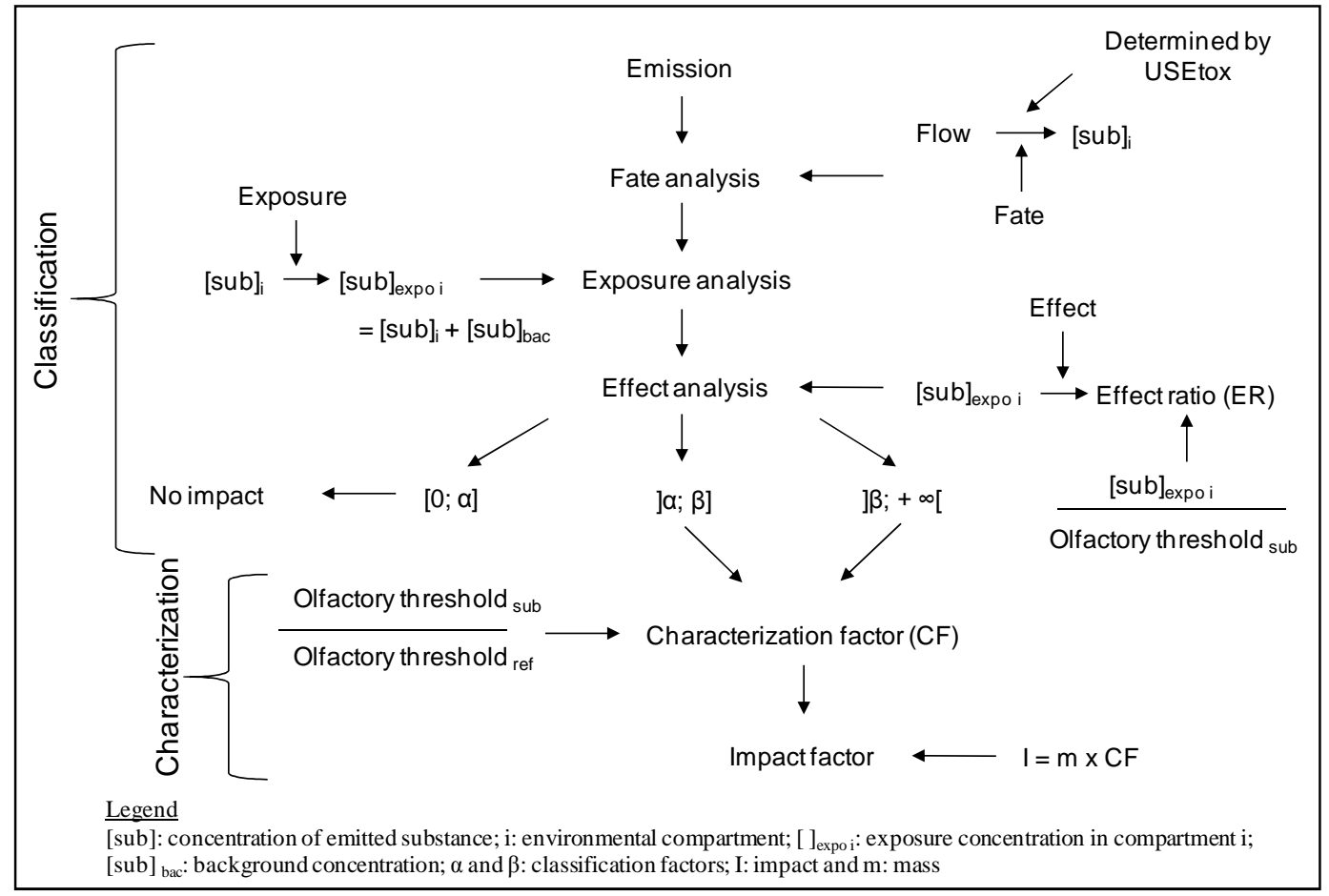

Figure 8: The new methodology framework

This methodological proposal deeply modifies the roles of the classification and characterization steps. Indeed, in traditional LCA, classification is a simple qualitative step to associate compound emission with different impact categories. In this work, the classification step is more important and characterization is aimed at computing the characterization factor. The change in this classification step allows for working on the occurrence of odour impacts. This methodological point is developed in the discussion section.

To illustrate our methodological proposal, here is an example with emission of ethyl benzene during composting of municipal solid waste.

\section{Case study with ethyl benzene emission during composting}

This case study aims to provide an example of odorous compound that can be analyzed using the new methodology. We chose ethyl benzene, which belongs to the family of halogenated volatile organic compounds (VOC). To develop the methodology, we used data from a French project named "CleanWasT" (ANR-08-ECOT-004 - "Assessment of clean and sustainable waste management technologies"). During the project, we measured several VOCs related to the functioning of a composting plant.

We chose ethyl benzene for two reasons:

- It is one of the analyzed compounds that displayed high concentrations;

- Its odour type is specific: "solvent and hydrocarbon";

The methodological steps are presented following Figure 4. We chose to localize ethyl benzene emission in the Brittany area (French west region).

\subsection{Emission characteristics}

Ethyl benzene emission occurs in silo ventilator outlets. The type of emission is smokestack. Ethyl benzene concentration is $10.68 \mathrm{~kg} \cdot \mathrm{y}^{-1}$, or $2.93 \cdot 10^{-2} \mathrm{~kg} \cdot \mathrm{d}^{-1}$. 


\subsection{Fate analysis}

We hypothesised that it was emitted it in a French county in the Brittany region (west of France). The local data for that territory are collected in landscape spreadsheets of the USEtox model (Tab 1). To analyze odour impact, we modelled the "facility" box with the following dimensions: a $2,500 \mathrm{~m}^{2}$ square (corresponding to the average dimensions of composting plants) and a local box represented by a $36 \mathrm{~km}^{2}$ square corresponding to the average dispersion area of odorous compounds $(3 \mathrm{~km})$. The environmental characteristics of the facility box are identical to the local box because USEtox is a nested model and box dimensions are very similar.

Tab 1: Environmental parameters applied to our methodology in the ethyl benzene case

\begin{tabular}{|c|c|c|c|}
\hline Environmental box & Environmental data & Modified value & Default value \\
\hline \multirow[t]{14}{*}{ Local box } & Land area & $22.12 \mathrm{~km}^{2}$ & $9.01 .10^{6} \mathrm{~km}^{2}$ \\
\hline & Sea area & $13.88 \mathrm{~km}^{2}$ & $9.87 .10^{5} \mathrm{~km}^{2}$ \\
\hline & Fresh water fraction area & 0.0045 & 0.03 \\
\hline & Natural soil fraction area & 0.0865 & 0.485 \\
\hline & Agricultural soil fraction area & 0.8485 & 0.485 \\
\hline & Other soils fraction area & 0.0605 & $1.00 .10^{-20}$ \\
\hline & Temperature & $11.3^{\circ} \mathrm{C}$ & $12^{\circ} \mathrm{C}$ \\
\hline & Wind speed & $3.5 \mathrm{~m} . \mathrm{s}^{-1}$ & $3 \mathrm{~m} \cdot \mathrm{s}^{-1}$ \\
\hline & Rain rate & $669 \mathrm{~mm} \cdot \mathrm{y}^{-1}$ & $700 \mathrm{~mm} \cdot \mathrm{y}^{-1}$ \\
\hline & Fresh water depth & $2.5 \mathrm{~m}$ & $2.5 \mathrm{~m}$ \\
\hline & $\begin{array}{l}\text { River flow from continental to } \\
\text { global or from global to } \\
\text { continental }\end{array}$ & 0.32 & 0 \\
\hline & Run-off fraction & 0.25 & 0.25 \\
\hline & Infiltrated Fraction & 0.25 & 0.25 \\
\hline & Soil erosion & $0.03 \mathrm{~mm} \cdot \mathrm{y}^{-1}$ & $0.03 \mathrm{~mm} \cdot \mathrm{y}^{-1}$ \\
\hline \multirow[t]{3}{*}{ Facility box } & Land area & $0.0025 \mathrm{~km}^{2}$ & $240 \mathrm{~km}^{2}$ \\
\hline & Natural soil fraction area & 0.05 & 0.67 \\
\hline & $\begin{array}{l}\text { Area fraction other soils } \\
\text { fraction area }\end{array}$ & 0.95 & 0.33 \\
\hline
\end{tabular}

Ethyl benzene concentration in the facility air compartment and in the local air compartment is therefore estimated to be $1.21 .10^{-14} \mathrm{~kg} \cdot \mathrm{m}^{-3}$. Because we considered an average daily emission and calculated a steady-state concentration, emission peaks do not appear.

\subsection{Exposure analysis}

According to the European Monitoring and Evaluation Program (EMEP) database on air quality measurement, we admit an ethyl benzene background concentration in urban air of $1.40 .10^{-10}$ $\mathrm{kg} \cdot \mathrm{m}^{-3}$ [15]. In this case, the exposure concentration is equal to the environmental concentration, i.e. $1 \cdot 40 \cdot 10^{-10} \mathrm{~kg} \cdot \mathrm{m}^{-3}$.

\subsection{Effect analysis}

According to Cometto-Muniz and Abraham [16], the olfactory threshold of ethyl benzene is 2.6.10 $\mathrm{kg}^{-8} \mathrm{~kg} \cdot \mathrm{m}^{-3}$. The effect ratio for ethyl benzene emission is calculated from the exposure concentration $\left(1.40 .10^{-10} \mathrm{~km} / \mathrm{m}^{3}\right)$ and the olfactory threshold. In this case, the effect ratio is $2.6 .10^{-8}$ $\mathrm{kg} \cdot \mathrm{m}^{-3}$. The effect ratio as related to ethyl benzene emission is $5.38 \cdot 10^{-3}$. 
To determine interval limits, we used a safety factor of $10^{-1}$ for the first limit, and the second limit was 1 . We then defined our three classification intervals:

- $\quad\left[0 ; 1.10^{-3}\right]$ : no impact is expected in that zone;

- $\left.\quad] 1.10^{-3} ; 1\right]$ : in that interval, we admit the existence of a "fuzzy zone" where the olfactory impact risk is not clearly identified;

- $\quad] 1 ;+\infty[$ : there is a clearly identified olfactory impact risk.

For the ethyl benzene example, the effect ratio falls into the second interval. We therefore admit there is an olfactory impact risk potential related to ethyl benzene emission during the composting of municipal solid waste.

\subsection{Quantification of the characterization factor and of odour impact}

To calculate the characterization factor of ethyl benzene emission, it is necessary to select a reference compound corresponding to its odour type. In the compost odour wheel (Figure 7), we classified ethyl benzene in the solvent/hydrocarbon odour type. For that odour type, the reference compound is benzene. According to Nagata (2003), benzene olfactory threshold is $8.6 .10^{-6} \mathrm{~kg} \cdot \mathrm{m}^{-3}$ [17]. Based on ethyl benzene and benzene olfactory thresholds, we calculated a characterization factor: $3.02 .10^{-3} \mathrm{~kg}$ eq. benzene.kg emitted ethyl benzene ${ }^{-1}$.

Finally, based on the characterization factor and ethyl benzene mass (from inventory step: 2.93.10 ${ }^{2} \mathrm{~kg} \cdot \mathrm{d}^{-1}$ ), we quantified the impact: $6 \cdot 6 \cdot 10^{-5} \mathrm{~kg}$ eq benzene. $\mathrm{d}^{-1}$.

This numerical value should not be considered independently. The proposed methodology allows for quantifying the impact of odour as related to municipal solid waste treatment in order to compare it to other odour impact quantifications in alternative waste treatment scenarios. Furthermore, our methodology cannot be compared to other characterization methods because current methods do not take into account the impact of odours.

\section{Discussion}

The main objective of this paper was to determine the impact pathway of a new impact category: odour. The next part is dedicated to the interest and limits of this new methodology.

\subsection{Impact of odour in waste management}

The aim of the methodology was to develop an impact pathway of a new impact category: odour. In order to use it in waste management system comparisons, the users have to be able to provide reliable and exhaustive characterization of the impact of odour in all compared systems. However, literature about emissions during the composting process is very poor and available information is very heterogeneous as it depends on the composition of input waste and on the composting process. In the coming years, data availability and their range should be improved and this methodology should be more applicable.

\subsection{Odours result from a cocktail of compounds}

The odours people can smell do not usually result from just one compound but are due to cocktails of compounds. Some synergistic and antagonistic phenomena still remain undetermined. Therefore such phenomena were not taken into account in our new methodology because of the lack of basic knowledge in that field. 
Currently, in our newly-developed methodology, a ratio < 1 means no impact. However, we observed odour impacts when the ratio was lower than one. This observation is linked to the cocktail effect which is not taken into account.

\subsection{Limitations of a steady-state system}

Most models are built according to a steady-state calculation in order to assess transfer and degradation phenomena and a resulting compound concentration in different environmental compartments (air, water and soil). Therefore, these models need daily emission and users have to calculate an average daily emission for the functional unit. This average daily emission is used on an infinite time-scale by the models. Then two important limitations can be observed:

- Calculating average daily emissions erases emission peaks of odorous compounds. And yet odour phenomena are frequently due to emission peaks, not to chronic emission;

- The resulting concentration represents the concentration at the steady-state and not the peak just after emission that causes olfactory discomfort.

These limitations are linked to the difference in persistence between compound emission and their consideration for odour impact assessment.

\subsection{Contribution of the new methodology}

In conventional LCA, a qualitative link between a compound and its potential impacts is made. This link depends on the potential polluting character of the compound. Impact occurrence is a function of intensity and occurrence probability, and occurrence probability determines impact appearance. This parameter strongly depends on local conditions and is not assessed in conventional LCA. To assess it, it is necessary to include local conditions.

\section{Conclusions}

In the French context of municipal solid waste management, local decision-makers use an environmental assessment tool called LCA to assess the environmental impacts of the different waste management scenarios. The global character of LCA leads to irrelevant assessment of local impacts because local impacts depend on local characteristics of the emission source and on impacted environments. However, in waste management and decision-making, the place of local impacts is very important and their assessment should be as robust as possible. Olfactory discomfort is one of these relevant local issues for the environmental assessment of waste management.

To assess the impact of odour with LCA, it is necessary to develop a new impact pathway because this impact category does not exist yet. The objective of this paper is to explain the construction of this impact pathway and take ethyl benzene as an example. The methodological proposal is built according to the partial cause and effect chain with the following items: emission characteristics, fate analysis, exposure analysis and effect analysis. The methodology is applicable in a general way. We chose to apply it to municipal solid waste management because of its local issues.

The application of our methodology to ethyl benzene emission allowed us to obtain an impact result of $6.6 \cdot 10^{-5} \mathrm{~kg}$ eq benzene. $\mathrm{d}^{-1}$. This numerical value should not be considered independently. Our methodology allows for quantifying the impact of odours related to municipal solid waste treatment plants and comparing it to other odour impact quantification for alternative waste treatment scenarios.

This work is the first step in odour impact assessment and aiming to have odours taken into account in waste management decision-making. To integrate our methodological proposal into future assessment tools it will be necessary to supply databases with odour measurements, i.e. data measured in composting plants, background concentrations, olfactory thresholds... Our new 
methodology also needs to be improved by understanding and integrating the cocktail effect between compounds. It determines odour impact (midpoint), not olfactory annoyance (endpoint). In order to characterize olfactory annoyance, it appears necessary to integrate social sciences into our approach.

\section{ACKNOWLEDGMENTS}

The authors would like to thank Pr. Bellon-Maurel V. (ELSA-Irstea) for his helpful comments on the manuscript. They also would like to thank the members of the CleanWasT and Proddeval (convention number 0906C0081) projects.

\section{REFERENCES}

1. European Commission: Europe in figures - Eurostat yearbook 2011. http://epp.eurostat.ec.europa.eu/portal/page/portal/eurostat/home (2011). Accessed Sept. 25,2012

2. Directive 2008/98/CE: Directive 2008/98/CE du Parlement Européen et du Conseil du 19 Novembre 2008 relative aux déchets et abrogeant certaines directives. In. Journal officiel de l'Union Européenne, (2008)

3. Loi n²009-967: Loi n ${ }^{\circ} 2009-967$ du 3 août 2009 de programmation relative à la mise en œuvre du Grenelle de l'environnement. In. Journal Officiel, (2009)

4. ISO 14040: Environmental management - Life cycle assessment - Principles and framework. In, vol. ISO 14040. International Standard Organization, (2006)

5. ISO 14044: Environmental management - Life Cycle Assessment - Requirements and guidelines. In, vol. ISO 14044. International Standard Organization, (2006)

6. Potting, J., Hauschild, M.: The linear nature of environmental impact from emissions in lifecycle assessment. Int. J. Life Cycle Assess. 2(3), 171-177 (1997).

7. Potting, J., Hauschild, M.: Spatial differentiation in life-cycle assessment via the site-dependent characterization of environmental impact from emissions. Int. J. Life Cycle Assess. 2(4), 209-216 (1997).

8. Cleary, J.: The incorporation of waste prevention activities into life cycle assessments of municipal solid waste management systems: Methodological issues. Int. J. Life Cycle Assess. 15(6), 579-589 (2010).

9. Ministère de l'Écologie, du Développement Durable et de l'Énergie: Inspection des Installations Classées. $\quad$ http://www.installationsclassees.developpement-durable.gouv.fr/3-Lesodeurs.html. Accessed Sept. 25, 2012

10. AATAMILA, M., VERKASALO, P.K., KORHONEN, M.J., SUOMINEN, A.L., HIRVONEN, M.R., VILUKSELA, M.K., NEVALAINEN, A.: Odour annoyance and physical symptoms among residents living near waste treatment centres. Environmental Research 111(1), 164-170 (2011).

11. Aissani, L.: Integration of spatial and temporal parameters and the risk of accident to the Life Cycle Assessment: Application to hydrogen and gasoline patterns. In., p. 352. $\mathrm{PhD}$ School of Mines (France), (2008)

12. Rosenbaum, R.K., Huijbregts, M.A.J., Henderson, A.D., Margni, M., McKone, T.E., van de Meent, D., Hauschild, M.Z., Shaked, S., Li, D.S., Gold, L.S., Jolliet, O.: USEtox human exposure and toxicity factors for comparative assessment of toxic emissions in life cycle analysis: sensitivity to key chemical properties. Int. J. Life Cycle Assess., 1-18 (2011).

13. Hauschild, M.Z., Huijbregts, M., Jolliet, O., Macleod, M., Margni, M., Van De Meent, D., Rosenbaum, R.K., McKone, T.E.: Building a model based on scientific consensus for life cycle impact assessment of chemicals: The search for harmony and parsimony. Environmental Science and Technology 42(19), 7032-7037 (2008).

14. Rosenfeld, P.E., Clark, J.J.J., Hensley, A.R., Suffet, I.H.: The use of an odour wheel classification for the evaluation of human health risk criteria for compost facilities. Water Science and Technology 55(5), 345-357 (2007).

15. European monitoring and Evaluation Program: EMEP VOC data. http://www.emep.int/index.html. Accessed Sep.25, 2012

16. Cometto-Muniz, J.E., MAbraham, M.H.: Olfactory detectability of homologous $n$ alkylbenzenes as reflected by concentration-detection functions in humans. Neuroscience 161, 236-248 (2009). 
17. Nagata, Y.: Measurement of odour threshold by triangle odour bag method. In., pp. 118-127. Ministry of the Environment, Government of Japan, Odor measurement review, Office of Odor, Noise and Vibration Environmental Management Bureau, (2003)

\section{FIGURES LEGENDS}

Figure 1: French household waste in 2009 (million tons)

Figure 2: Scope of LCA applied to MSW management

Figure 3: Complete odour impact pathway

Figure 4: Cause/effect chain of environmental impact

Figure 5: The USEtox framework

Figure 6a and b: USEtox box translation (from a) to b)) for local impact assessment and transfers between environmental boxes and compartments

Figure 7: Compost odour wheel

Figure 8: The new methodology framework 